\title{
Hematologic changes predict clinical outcome in recovered patients with COVID-19
}

\author{
Jian Mao ${ }^{1,4} \cdot$ Rong Dai ${ }^{2} \cdot$ Rui-Chan $\mathrm{Du}^{1,4} \cdot$ Yan Zhu ${ }^{3} \cdot$ Li-Ping Shui ${ }^{1} \cdot$ Xiao-Hua Luo ${ }^{1,4}$ (I) \\ Received: 17 November 2020 / Accepted: 11 January 2021 / Published online: 1 February 2021 \\ (C) The Author(s), under exclusive licence to Springer-Verlag GmbH, DE part of Springer Nature 2021
}

\begin{abstract}
2019 coronavirus disease (COVID-19) presents as a newly recognized pneumonia that has brought about a global pandemic and is increasingly considered as a systemic illness. We investigated the clinical and laboratory features of recovered COVID-19 patients without pre-existing hematologic diseases at Wuhan No. 1 Hospital. Fifty-nine male and 68 female Chinese patients were included with the median age at 64 years in the present study. Eosinopenia (37.80\%), monocytosis (51.97\%), lymphocytopenia $(25.20 \%)$, and anemia $(51.97 \%)$ were the most common hematologic findings in our cohort, particularly in severe or critically ill COVID-19. The levels of changes in leukocytes, neutrophils, lymphocytes, monocytes, eosinophils, basophils, platelets, hemoglobin levels, mean corpuscular volume (MCV), and mean cell hemoglobin concentration (MCHC) are overall associated with lung involvement, oxygen demand, and disease activity. However, changes of eosinophils (end hospitalization-baseline) (coefficients $=10.32 ; 95 \% \mathrm{CI}=1.03-19.60, P=0.03)$ and basophils $(\mathrm{Max}-\mathrm{Min})(\mathrm{coefficients}=$ $71.43 ; 95 \% \mathrm{CI}=8.55-134.31, P=0.03$ ) were independent predictors of delayed recovery in the hospital by the multivariate analysis in this recovered population. A variety of hematologic changes are associated with the severity and clinical outcome of recovered COVID-19 patients, which warrants further exploration of their underlying mechanisms.
\end{abstract}

Keywords 2019 coronavirus disease $\cdot$ COVID-19 $\cdot$ Hematologic $\cdot$ Eosinopenia

\section{Introduction}

Since December 2019, the coronavirus disease 2019 (COVID-19)-infected pneumonia brings about global pandemic $[1,2]$. As of July 15, 2020, 13,150,645 patients were globally infected with 574,464 deaths reported to the WHO

Jian Mao and Rong Dai contributed equally to this work and should be considered as first authors.

Xiao-Hua Luo

xiaohua.luo@gmail.com

1 Department of Hematology, The First Affiliated Hospital of Chongqing Medical University, 1 Youyi Road, Yuzhong District, Chongqing 400016, People's Republic of China

2 Department of Cardiology, Wuhan No.1 Hospital, Zhongshan Avenue 215\#, Wuhan 430022, Hubei, China

3 Department of Hematology, Southwest Hospital, Third Military Medical University (Army Medical University), Chongqing 400038, China

4 Eighth Batch Chongqing Medical Aid Team to Wuhan City of Hubei Province, Chongqing, People's Republic of China
[3]. The natural reservoir and intermediate host of COVID-19 have not been identified, but several wildlife species, including bats and pangolins [4], have shown laboratory evidence of infection with a related coronavirus. Virus infection could cause a variety of hematologic changes. Recently, lymphocytopenia, neutrophil-to-lymphocyte ratio, and platelets were identified as risk factors for survival in patients with COVID-19 [5-8]. Little attention has been paid to the course of recovered patients since the majority of COVID-19 patients would survive in the end. The report explored the hematologic manifestations in recovered patients with COVID-19 who were treated at Wuhan No. 1 Hospital.

\section{Materials and methods}

\section{Study population}

Our study included adult patients who were diagnosed as COVID-19 and were treated and recovered at Wuhan No. 1 Hospital but excluded patients with a history of hematologic diseases. Two hundred fifteen patients with suspected 
COVID-19 and clinical outcomes were identified on April 13, 2020. Eighty-one patients without confirmed COVID-19 and 7 COVID-19 patients who died were excluded, and 127 patients finally enrolled in this analysis. Based on the criteria for COVID-19 defined by WHO interim guidance, the diagnosis was confirmed by a positive reverse transcriptase-polymerase chain reaction (RT-PCR) assay for SARS-CoV-2 in a respiratory tract sample tested (the local Center for Disease Control or a designated diagnostic laboratory). All COVID-19 patients were classified as being mild, moderate, severe, or critically ill according to the Chinese management guideline for COVID19 (7th edition) released by the National Health Commission of China [9]. The study was approved by the Research Ethics Commission of Wuhan No. 1 Hospital (W202004-5), and written informed consent was waived due to emerging infectious diseases. All the recovered patients with COVID-19 had entirely relieved symptoms, significantly improved function in lung and other organs, and no need for supportive treatment as well as viral clearance confirmed by consecutive negative tests for SARS-Cov-2 [10].

\section{Laboratory studies}

Initial hematologic findings composed a complete blood count $(\mathrm{CBC})$ and serum biochemistry (including liver and kidney function, lactate dehydrogenase, and electrolytes), myocardial enzymes, interleukin-6 (IL-6), C-reactive protein (CRP), and procalcitonin (PCT). Nasal and pharyngeal swabs, or sputum, were detected to exclude other viral infections, including influenza, respiratory syncytial virus, parainfluenza virus, and adenovirus. Computed tomogram (CT) scans or chest radiographs were also done for all patients. We monitored these parameters until the patients were discharged from the hospital or dead. The CT features were evaluated as follows: lung region distribution (unilateral or bilateral), degree of involvement (mild $<25 \%$, moderate $25-50 \%$, severe $>$ $50 \%$ ), and transverse distribution (peripheral or diffuse).

\section{Data collection, analysis, and definition}

We analyzed the reported clinical and laboratory features. The clinical composite endpoint was the deterioration of disease and duration of hospital stay. Univariate analysis was conducted to compare patients who reached the endpoint and those who did not by the non-parametric Mann-Whitney test. We then accessed independent predictors of the endpoint after adjusting sex, age, and comorbidities at presentation by multiple logistic regression or multiple linear regression analysis with stepwise selection. Baseline variables and peak/nadir variables were used to predict an outcome, and those with $P$ values below 0.20 in univariate analyses were included as explanatory variables. All $P$ values were two-tailed and statistical significance was defined as $P$ less than 0.05 . We used
Stata software version 15 (StataCorp, College Station, TX) and GraphPad Prism 5.0 (GraphPad Software, Inc., San Diego, CA) for all analyses. Continuous data were reported as means (standard deviations) or medians (interquartile ranges, IQR), and categorical variables were presented as numbers (percentages).

For the definition of leukopenia, neutropenia, lymphocytopenia, monocytopenia, eosinopenia, and basopenia, we used cutoff values of $<4 \times 10^{9} / \mathrm{L},<1.5 \times 10^{9} / \mathrm{L},<1 \times 10^{9} / \mathrm{L}$, $<0.1 \times 10^{9} / \mathrm{L},<0.05 \times 10^{9} / \mathrm{L}$, and $<0.01 \times 10^{9} / \mathrm{L}$, respectively. Leukocytosis, neutrophilia, lymphocytosis, monocytosis, eosinophilia, and basophilia are defined by a cell count higher than the upper reference limit, which is commonly $10 \times 10^{9} / \mathrm{L}, 7.5 \times 10^{9} /$ $\mathrm{L}, 4 \times 10^{9} / \mathrm{L}, 0.6 \times 10^{9} / \mathrm{L}, 0.5 \times 10^{9} / \mathrm{L}$, and $0.1 \times 10^{9} / \mathrm{L}$ in adult patients, respectively.

\section{Results}

\section{Patient characteristics}

Between February 12 and March 18, 127 moderate, severe, or critically ill patients with COVID-19 were admitted or transferred to Wuhan No. 1 Hospital. At this point, all patients had been discharged, except four patients who were transferred to another hospital, and no patients had died. These patients had no history of hematologic diseases. This study included 59 male and 68 female patients with a median age at 64 years (range 26-87 years), all ethnic Chinese (Table 1). Seventy-four of 127 patients (58.27\%) had underlying diseases - hypertension $(47,37 \%)$ and diabetes $(25,20 \%)$ were most frequent. Fever $(93,73 \%)$, cough $(87,69 \%)$, and fatigue $(51,40 \%)$ were the most prevalent symptoms at disease onset in these recovered patients. Hydroxychloroquine was used since March 20 according to the guideline [11]. Intravenous methylprednisolone at $1-2 \mathrm{mg} / \mathrm{kg}$ was given to 35 patients with respiratory distress or rapid progression on their chest radiographs. One hundred twenty-three (97\%) patients received antiviral treatment, $89(70 \%)$ were given empirical antibiotics, and $6(5 \%)$ were given intravenous gamma globulin therapy. Thymosin $\alpha 1$ was administered in 12 (9.4\%) patients. Non-invasive mechanical ventilation and invasive mechanical ventilation were required in 3 and 3 patients, respectively. Tocilizumab was used to target cytokine storm in one patient with high levels of IL-6. Patients with severe/critically ill COVID-19 were significantly older than moderate patients (median 68 versus 62 years; $P=0.003$ ), with frequent dyspnea ( $42 \%$ versus $7 \% ; P<$ $0.001)$, more likely receiving glucocorticoid (53\% versus $13 \%, P$ $<0.001$ ), or less likely receiving traditional Chinese medicine treatment $(60 \%$ versus $83 \%, P=0.004)$. More patients with severe/critically ill COVID-19 received high-flow nasal cannula (24\% versus $1 \%, P<0.001)$ or mechanical ventilation $(13 \%$ versus $0, P=0.002$ ) while more moderate patients were supplied with low-flow nasal cannula ( $80 \%$ versus $51 \%, P=0.001)$. 
Table 1 Clinical characteristics and treatment of recovered patients with COVID-19

\begin{tabular}{|c|c|c|c|c|}
\hline & Total $(n=127)$ & Moderate $(n=82)$ & Severe or critically ill $(n=45)$ & $P$ value \\
\hline Median (IQR) age, years & $64(56-71)$ & $62(53-68)$ & $68(61-73)$ & 0.003 \\
\hline$<40$ years & $6(5 \%)$ & $6(7 \%)$ & 0 & \\
\hline $40-59$ years & $38(30 \%)$ & $27(33 \%)$ & $11(24 \%)$ & \\
\hline$\geq 60$ years & $83(65 \%)$ & $49(60 \%)$ & $34(76 \%)$ & \\
\hline Sex & & & & 0.684 \\
\hline Female & $68(54 \%)$ & $45(55 \%)$ & $23(51 \%)$ & \\
\hline Male & $59(46 \%)$ & $37(45 \%)$ & $22(49 \%)$ & \\
\hline \multicolumn{5}{|l|}{ Comorbidities } \\
\hline Hypertension & $47(37 \%)$ & $27(33 \%)$ & $20(44 \%)$ & 0.199 \\
\hline Diabetes & $25(20 \%)$ & $12(15 \%)$ & $13(29 \%)$ & 0.053 \\
\hline Cardiovascular disease & $9(7 \%)$ & $5(6 \%)$ & $4(9 \%)$ & 0.720 \\
\hline Chronic heart failure & $1(1 \%)$ & 0 & $1(2 \%)$ & 0.354 \\
\hline Chronic lung diseases & $10(8 \%)$ & $4(5 \%)$ & $6(13 \%)$ & 0.164 \\
\hline Malignancy & $3(2 \%)$ & 0 & $3(7 \%)$ & 0.043 \\
\hline Hepatitis B virus surface antigen positivity & $2(2 \%)$ & $1(1 \%)$ & $1(2 \%)$ & 1.000 \\
\hline Cerebrovascular disease & $7(6 \%)$ & $2(2 \%)$ & $5(11 \%)$ & 0.096 \\
\hline Chronic kidney disease & $1(1 \%)$ & $1(1 \%)$ & 0 & 1.000 \\
\hline Gastrointestinal diseases & $3(2 \%)$ & $1(1 \%)$ & $2(4 \%)$ & 0.286 \\
\hline \multicolumn{5}{|l|}{ Symptoms at disease onset } \\
\hline Fever & $93(73 \%)$ & $60(73 \%)$ & $33(73 \%)$ & 0.984 \\
\hline Cough & $87(69 \%)$ & $57(70 \%)$ & $30(67 \%)$ & 0.741 \\
\hline Fatigue & $51(40 \%)$ & $32(39 \%)$ & $19(42 \%)$ & 0.725 \\
\hline Myalgia & $17(13 \%)$ & $10(12 \%)$ & $7(16 \%)$ & 0.595 \\
\hline Dyspnea & $25(20 \%)$ & $6(7 \%)$ & $19(42 \%)$ & $<0.001$ \\
\hline Chest tightness & $32(25 \%)$ & $18(22 \%)$ & $14(31 \%)$ & 0.255 \\
\hline Sputum production & $32(25 \%)$ & $25(30 \%)$ & $7(16 \%)$ & 0.087 \\
\hline Pharyngalgia & $4(3 \%)$ & $3(4 \%)$ & $1(2 \%)$ & 1.000 \\
\hline Diarrhea & $9(7 \%)$ & $5(6 \%)$ & $4(9 \%)$ & 0.720 \\
\hline Anorexia & $1(1 \%)$ & $1(1 \%)$ & 0 & 1.000 \\
\hline Nausea & $6(5 \%)$ & $2(2 \%)$ & $4(9 \%)$ & 0.184 \\
\hline Vomiting & $5(4 \%)$ & $2(2 \%)$ & $3(7 \%)$ & 0.346 \\
\hline Abdominal pain & $2(2 \%)$ & $1(1 \%)$ & $1(2 \%)$ & 1.000 \\
\hline Dizziness & $9(7 \%)$ & $6(7 \%)$ & $3(7 \%)$ & 1.000 \\
\hline Median (IQR) time from onset of symptom to hospital admission, days & $11(7-18)$ & $14(7-19)$ & $10(7-15)$ & 0.199 \\
\hline \multicolumn{5}{|c|}{ Treatment } \\
\hline Antiviral therapy & $123(97 \%)$ & $80(98 \%)$ & $43(96 \%)$ & 0.614 \\
\hline Glucocorticoid therapy & $35(28 \%)$ & $11(13 \%)$ & $24(53 \%)$ & $<0.001$ \\
\hline Antibiotics & $89(70 \%)$ & $54(66 \%)$ & $35(78 \%)$ & 0.160 \\
\hline Intravenous immunoglobulin therapy & $6(5 \%)$ & $3(4 \%)$ & $3(7 \%)$ & 0.665 \\
\hline Thymosin & $12(9 \%)$ & $8(10 \%)$ & $4(9 \%)$ & 1.000 \\
\hline Hydroxychloroquine & $18(14 \%)$ & $10(12 \%)$ & $8(18 \%)$ & 0.388 \\
\hline Traditional Chinese medicine treatment & $95(75 \%)$ & $68(83 \%)$ & $27(60 \%)$ & 0.004 \\
\hline Oxygen treatment & $107(84 \%)$ & $67(82 \%)$ & $40(89 \%)$ & 0.322 \\
\hline Low-flow nasal cannula & $89(70 \%)$ & $66(80 \%)$ & $23(51 \%)$ & 0.001 \\
\hline High-flow nasal cannula & $12(9 \%)$ & $1(1 \%)$ & $11(24 \%)$ & $<0.001$ \\
\hline Mechanical ventilation & $6(5 \%)$ & 0 & $6(13 \%)$ & 0.002 \\
\hline Non-invasive & $3(2 \%)$ & 0 & $3(7 \%)$ & 0.043 \\
\hline Invasive & $3(2 \%)$ & 0 & $3(7 \%)$ & 0.043 \\
\hline Median (IQR) time from hospital admission to the outcome, days & $28(25-31)$ & $28(24-31)$ & $29(27-32)$ & 0.150 \\
\hline
\end{tabular}

IQR (interquartile range) is given wherever necessary

Levels of aspartate aminotransferase elevated in 21 of 123 (17\%) cases (Table 2). Sixty-eight of 69 (99\%) patients had normal levels of serum PCT $(<0.05 \mathrm{ng} / \mathrm{mL})$. Of patients with available data, concentrations of CRP and IL- 6 were significantly higher in 50 of $114(44 \%)$ and 18 of $63(29 \%)$ patients. Abnormalities on chest $\mathrm{CT}$ were observed in all patients with bilateral lesions in 121 (95\%) patients (Table 2). Subjects with severe/critically ill COVID-19 tended to have lower levels of albumin (median $33.4 \mathrm{~g} / \mathrm{L}$ versus $35.7 \mathrm{~g} / \mathrm{L} ; P=0.002$ ), and higher levels of lactate dehydrogenase (median $252 \mathrm{U} / \mathrm{L}$ versus $190 \mathrm{U} / \mathrm{L} ; P=0.007$ ), blood urea nitrogen (median 4.7 $\mathrm{mmol} / \mathrm{L}$ versus $3.9 \mathrm{mmol} / \mathrm{L} ; P=0.036$ ), interleukin-6 (median $6.43 \mathrm{pg} / \mathrm{mL}$ versus $1.7 \mathrm{pg} / \mathrm{mL} ; P=0.001$ ), hypersensitive cardiac troponin I (median $0.009 \mu \mathrm{g} / \mathrm{L}$ versus $0.005 \mu \mathrm{g} / \mathrm{L} ; P$ $=0.017)$, and C-reactive protein $(>5 \mathrm{mg} / \mathrm{L}: 59 \%$ versus $36 \%$, $P=0.018)$. Patients who developed severe/critically ill COVID-19 had more lung involvements and diffuse pneumonia $(69 \%$ versus $29 \%, P<0.001)$ compared to moderate cases. 


\section{Leukocyte, neutrophils, and monocytes}

Twenty-two patients (17.32\%) developed leukocytosis during the first month of illness, with nine patients $(7.09 \%)$ on admission (Fig. 1). Transient leukopenia was observed in 28 patients during their first month with 18 (14.17\%) of patients on admission. Twenty-two patients developed neutrophilia mostly during the first month of illness with seven patients $(5.51 \%)$ at admission. Transient neutropenia was observed in 9 patients during their clinical course at the hospital.

Monocytosis occurred in 66 patients $(51.97 \%)$ during the first month, with 47 on admission. Monocytopenia was found in 2 patients during their disease course, with 1 of them had at admission. The majority of patients had a normal monocyte count at the disease onset. Progressive monocytosis happened early in the disease course and peaked on $11(0-32)$ days after admission in 89 patients who had blood sampled at more than three time points, but 30 of 89 patients remained monocytosis at the fourth week of COVID-19.

\section{Lymphocytes, eosinophils, and basophils}

Lymphocytopenia was found in $32(25.20 \%)$ cases during their course of illness, with 26 of them had at admission (Fig. 1). Lymphocytopenia progressively happened early and dropped to its nadir on $8(0-33)$ days after admission. The lymphocyte counts commonly restored on day 20 (434) after onset, but seven patients remained lymphopenic in the fourth week of COVID-19. Transient lymphocytosis was observed only in 3 patients during their first month.

Seven patients developed eosinophilia on day $24(0-31)$ with one on admission. Eosinopenia was observed in 48 (37.80\%), with 41 of them had on admission, and blood eosinophils were not detected at least once in $16.54 \%$ (21 of 127) of patients. Eosinopenia emerged early in the course of illness on $3(0-18)$ after admission and then recovered to normal levels gradually, but 11 remained eosinopenia in the fourth week of COVID-19. Similarly, the percentage of eosinophils increased steadily during the course (Figure S1). Basopenia was found in 17 (13.39\%), with 10 of them had on admission, and blood basophils were not detected at least once in $13.39 \%$ (17 of 127) of patients. Basopenia happened on 3 (0-33) days after admission and then returned to normal levels shortly. Seven of 127 (5.51\%) patients had both undetectable eosinophils and basophils in their peripheral blood. No patients experienced basophilia.

\section{Platelets and red blood cells}

Six patients experienced thrombocytopenia (platelet count $<$ $100 \times 10^{9} / \mathrm{L}$ ) during their hospital stay, and only one of them had a platelet count less than $50 \times 10^{9} / \mathrm{L}$ (Fig. 2). Thrombocytopenia in this group was self-limited and recovered by the end of 1 month. No patient had a massive hemorrhage or transfused platelet. Reactive thrombocytosis (platelet count $>400 \times 10^{9} / \mathrm{L}$ ) was noticed in 16 patients. The platelet count and thrombocytocrit (Figure S2) reach a peak on a median of day 7 of disease (range 1-32). No evidence of thromboembolism was found in all patients.

Sixty-five $(51.97 \%)$ patients had anemia in this hospital, with 44 cases on admission. The hemoglobin level dropped from baseline $126(60-160) \mathrm{g} / \mathrm{L}$ to $117(66-159) \mathrm{g} / \mathrm{L}$ at the end of the course (Fig. 2). It is confirmed by decreased red blood cell counts and hematocrit (HCT). Elevated mean corpuscular volume (MCV) from $89.05(60.1-99) \mathrm{fL}$ to 91.3 (61.6-105.7) fL and reduced mean cell hemoglobin concentration (MCHC) from 344 (311-401) g/L to 333 (267-357) g/ $\mathrm{L}$ in normal range were observed. We found no signs of significant bleeding, and only one patient required red blood cell transfusion. No evidence of hemolysis was observed in all patients.

\section{Hematologic changes in classified COVID-19 patients}

Leukocytosis, neutrophilia, monocytosis, and lymphocytopenia, eosinopenia, and anemia in severe or critically ill patients were significant compared to moderate patients with COVID-19 (Fig. $3 \mathrm{a}, \mathrm{b})$. This difference was further pronounced in the percentage of all cell subtypes (Figure S3A). Interestingly, we found higher $\mathrm{MCV}$ or lower MCHC in severe or critically ill patients than in moderate patients (Fig. 3b). It seems that severe or critically ill patients had higher mean platelet volume (MPV), red cell distribution width-standard deviation (RDW-SD), and platelet-large cell ratio (P-LCR) than moderate patients by the end of hospital stay (Figure S3B). No difference was observed in terms of platelet counts or thrombocytocrit, platelet distribution width (PDW), and red cell distribution width-coefficient of variation (RDW-CV).

\section{Levels of changes in eosinophils and basophils predict delayed recovery of COVID-19}

Univariate linear regression analysis implied that the presence of comorbidities at admission, high demand for oxygen, and the levels of changes in leukocytes, absolute neutrophil count (ANC), absolute lymphocyte count (ALC), absolute monocyte count (AMC), absolute eosinophil count (AEC), absolute basophil count (ABC), platelet (PLT), hemoglobin (HGB), $\mathrm{MCV}$, and $\mathrm{MCHC}$ were associated with disease progression. The presence of comorbidities at admission (coefficients = 2.27; 95\% confidence interval $(\mathrm{CI})=0.31-4.22, P=0.02)$, delta of AEC (end hospitalization - baseline) (coefficients = $10.32 ; 95 \% \mathrm{CI}=1.03-19.60, P=0.03)$, and delta of $\mathrm{ABC}$ $($ Max - Min $)($ coefficients $=71.43 ; 95 \% \mathrm{CI}=8.55-134.31, P$ $=0.03$ ) were independent predictors of delayed recovery in the hospital by the multivariate analysis (Table 3 ). 
Table 2 Laboratory and chest CT findings in recovered patients with COVID-19

\begin{tabular}{|c|c|c|c|c|}
\hline Laboratory finding (normal range) & Total $=127$ & Moderate $(n=82)$ & $\begin{array}{l}\text { Severe or critically ill }(n= \\
45)\end{array}$ & $P$ value \\
\hline Median (IQR) alanine aminotransferase, U/L $(\leq 41)$ & $23(15.0-36.5)$ & $23(15.0-37.0)$ & $24.5(17-36)$ & 0.652 \\
\hline$>41 \mathrm{U} / \mathrm{L}$ & $21 / 123(17 \%)$ & $15 / 81(19 \%)$ & $6 / 42(14 \%)$ & 0.554 \\
\hline Median (IQR) aspartate aminotransferase, U/L $(\leq 40)$ & $26(20.0-35.0)$ & $26(19.0-35.0)$ & $27(21-34.8)$ & 0.719 \\
\hline$>40 \mathrm{U} / \mathrm{L}$ & $18 / 123(15 \%)$ & $12 / 81(15 \%)$ & $6 / 42(14 \%)$ & 0.937 \\
\hline Median (IQR) total protein, $\mathrm{g} / \mathrm{L}(60-80)$ & $64.3(59.9-67.5)$ & $64.7(60.2-68.0)$ & $63.1(59.3-66.7)$ & 0.305 \\
\hline$<60 \mathrm{~g} / \mathrm{L}$ & $32 / 123(26 \%)$ & $20 / 81(25 \%)$ & $12 / 42(29 \%)$ & 0.642 \\
\hline Median (IQR) albumin, g/L (35.0-50.0) & $34.4(31.2-37.6)$ & $35.7(32.1-38.7)$ & $33.4(27.4-35.6)$ & 0.002 \\
\hline$<35 \mathrm{~g} / \mathrm{L}$ & $65 / 123(53 \%)$ & $35 / 81(43 \%)$ & $30 / 42(71 \%)$ & 0.003 \\
\hline Median (IQR) total bilirubin, $\mu \mathrm{mol} / \mathrm{L}(\leq 24)$ & $11.2(8.5-14.4)$ & $10.9(8.4-14)$ & $11.45(9.08-17.43)$ & 0.185 \\
\hline$>24 \mu \mathrm{mol} / \mathrm{L}$ & $1 / 123(1 \%)$ & $0 / 81$ & $1 / 42(2 \%)$ & 0.341 \\
\hline Median (IQR) direct bilirubin, $\mu \mathrm{mol} / \mathrm{L}(\leq 7)$ & $1.4(0.8-2)$ & $1.4(0.9-1.9)$ & $1.3(0.48-2.7)$ & 0.920 \\
\hline$>7 \mu \mathrm{mol} / \mathrm{L}$ & $1 / 119(1 \%)$ & $0 / 79$ & $1 / 40(3 \%)$ & 0.336 \\
\hline Median (IQR) lactate dehydrogenase, U/L (114-250) & $218.5(166.3-274.5)$ & $190(164-256)$ & $252(194-373)$ & 0.007 \\
\hline$>350 \mathrm{U} / \mathrm{L}$ & $17 / 92(18 \%)$ & $5 / 57(9 \%)$ & $12 / 35(34 \%)$ & 0.004 \\
\hline Median (IQR) alkaline phosphatase, U/L (30-120) & $83(68.3-100.8)$ & $88(68.75-103.25)$ & $76(64-92.3)$ & 0.080 \\
\hline$>120 \mathrm{U} / \mathrm{L}$ & $12 / 110(11 \%)$ & $10 / 76(13 \%)$ & $2 / 34(6 \%)$ & 0.336 \\
\hline Median (IQR) blood urea nitrogen, mmol/L (1.8-7.3) & $4.2(3.4-5.3)$ & $3.9(3.4-5.1)$ & $4.7(3.6-5.8)$ & 0.036 \\
\hline$>7.3 \mathrm{mmol} / \mathrm{L}$ & $8 / 116(7 \%)$ & $4 / 77(5 \%)$ & $4 / 39(10 \%)$ & 0.439 \\
\hline Median (IQR) creatinine, $\mu \mathrm{mol} / \mathrm{L}$ (53-106) & $61(52-75.3)$ & $60(51-78)$ & $64(53.5-72.5)$ & 0.676 \\
\hline$<53 \mu \mathrm{mol} / \mathrm{L}$ & $32 / 116(28 \%)$ & $23 / 77(30 \%)$ & $9 / 39(23 \%)$ & 0.514 \\
\hline$>106 \mu \mathrm{mol} / \mathrm{L}$ & $5 / 116(4 \%)$ & $4 / 77(5 \%)$ & $1 / 39(3 \%)$ & 0.662 \\
\hline Median (IQR) uric acid, $\mu \mathrm{mol} / \mathrm{L}(208-428)$ & $279.5(234-349)$ & $289(250-366)$ & $263(214-342.5)$ & 0.071 \\
\hline$>428 \mu \mathrm{mol} / \mathrm{L}$ & $10 / 116(9 \%)$ & $8 / 77(10 \%)$ & $2 / 39(5 \%)$ & 0.492 \\
\hline Median (IQR) potassium, mmol/L (3.5-5.3) & $4.1(3.7-4.4)$ & $4.1(3.8-4.4)$ & $4.05(3.7-4.33)$ & 0.476 \\
\hline$<3.5 \mathrm{mmol} / \mathrm{L}$ & $8 / 116(7 \%)$ & $4 / 76(5 \%)$ & $4 / 40(10 \%)$ & 0.444 \\
\hline $3.5-5.3 \mathrm{mmol} / \mathrm{L}$ & $105 / 116(91 \%)$ & $71 / 76(93 \%)$ & $34 / 40(85 \%)$ & 0.184 \\
\hline$>5.3 \mathrm{mmol} / \mathrm{L}$ & $3 / 116(2 \%)$ & $1 / 76(1 \%)$ & $2 / 40(5 \%)$ & 0.117 \\
\hline Median (IQR) sodium, mmol/L (137-147) & $139.3(137.2-141.2)$ & $139.6(137.4-141.2)$ & $138.9(137-141.23)$ & 0.499 \\
\hline$<137 \mathrm{mmol}$ & $22 / 116(19 \%)$ & $12 / 76(16 \%)$ & $10 / 40(25 \%)$ & 0.229 \\
\hline$>147 \mathrm{mmol}$ & $1 / 116(1 \%)$ & $1 / 76(1 \%)$ & $0 / 40$ & 1.000 \\
\hline Median (IQR) interleukin-6, pg/mL $(\leq 7)$ & $2.8(1.5-8.18)$ & $1.7(1.5-3.8)$ & $6.43(3.13-11.7)$ & 0.001 \\
\hline$>7 \mathrm{pg} / \mathrm{mL}$ & $18 / 63(29 \%)$ & $9 / 43(21 \%)$ & $9 / 20(45 \%)$ & 0.049 \\
\hline Median (IQR) NT-proBNP, ng/L $(\leq 1800)$ & $151(43.5-347.5)$ & $89(34.5-232.75)$ & $208.5(87-593)$ & 0.253 \\
\hline$>1800 \mathrm{ng} / \mathrm{L}$ & $3 / 30(10 \%)$ & $0 / 14$ & $3 / 16(19 \%)$ & 0.228 \\
\hline $\begin{array}{l}\text { Median (IQR) hypersensitive cardiac troponin I, } \mu \mathrm{g} / \mathrm{L} \\
\quad(0.001-0.026)\end{array}$ & $0.006(0.003-0.009)$ & $0.005(0.002-0.008)$ & $0.009(0.005-0.013)$ & 0.017 \\
\hline$>0.026 \mu \mathrm{g} / \mathrm{L}$ & $2 / 42(5 \%)$ & $0 / 26$ & $2 / 16(13 \%)$ & 0.139 \\
\hline C-reactive protein, $\mathrm{mg} / \mathrm{L}(0-5)$ & $64 / 114(56 \%)$ & $47 / 73(64 \%)$ & $17 / 41(41 \%)$ & 0.008 \\
\hline$>5 \mathrm{mg} / \mathrm{L}$ & $50 / 114(44 \%)$ & $26 / 73(36 \%)$ & $24 / 41(59 \%)$ & 0.018 \\
\hline Procalcitonin, $\mu \mathrm{g} / \mathrm{L}(0-0.05)$ & $57 / 69(83 \%)$ & $37 / 42(88 \%)$ & $20 / 27(74 \%)$ & 0.353 \\
\hline$>0.05 \mu \mathrm{g} / \mathrm{L}$ & $12 / 69(17 \%)$ & $5 / 42(12 \%)$ & $7 / 27(26 \%)$ & 0.194 \\
\hline \multicolumn{5}{|l|}{ Chest CT findings } \\
\hline Lung region distribution & & & & 0.325 \\
\hline Unilateral & $6(5 \%)$ & $5(6 \%)$ & $1(2 \%)$ & \\
\hline Bilateral & $121(95 \%)$ & $77(94 \%)$ & $44(98 \%)$ & \\
\hline Degree of lung involvement & & & & $<0.001$ \\
\hline$<25 \%$ & $60(47 \%)$ & $51(62 \%)$ & $9(20 \%)$ & \\
\hline $25-50 \%$ & $54(43 \%)$ & $30(37 \%)$ & $24(53 \%)$ & \\
\hline
\end{tabular}


Table 2 (continued)

\begin{tabular}{|c|c|c|c|c|}
\hline Laboratory finding (normal range) & Total $=127$ & Moderate $(n=82)$ & $\begin{array}{l}\text { Severe or critically ill }(n= \\
45)\end{array}$ & $P$ value \\
\hline$>50 \%$ & $13(10 \%)$ & $1(1 \%)$ & $12(27 \%)$ & \\
\hline Transverse distribution & & & & $<0.001$ \\
\hline Peripheral & $72(57 \%)$ & $58(71 \%)$ & $14(31 \%)$ & \\
\hline Diffuse & $55(43 \%)$ & $24(29 \%)$ & $31(69 \%)$ & \\
\hline
\end{tabular}

IQR (interquartile range) is given wherever necessary. Values are numbers (\%) of patients with respective abnormalities unless otherwise indicated

\section{Blood cell counts in COVID-19 patients are correlated with lung involvement, oxygen demand, CRP, and IL- 6}

In patients with COVID-19, changes in delta leukocyte, neutrophil, monocyte, eosinophil counts, HGB, MCV, and PLT showed a positive correlation with oxygen demand and high levels of CRP (Table 4). In contrast, only changes in delta leukocyte, neutrophil, and monocyte counts are positively correlated with lung involvement while changes in delta eosinophils are positively related to levels of IL-6. COVID-19 patients with high levels of CRP or IL-6 more frequently had increased peak leukocyte, peak neutrophil, peak monocyte, peak MCV, and peak platelet with low nadir lymphocyte, nadir eosinophil, nadir basophil, nadir $\mathrm{HGB}$, and nadir MCHC. Patients with high CRP and IL-6 had significantly severe lung involvement and a higher demand for oxygen (Supplementary Table 1). Table 5 shows the correlation coefficients of various blood cells with one another. Most of the cell subtypes showed statistically positive linear relationships with one another while red blood cell count, HGB, HCT, and $\mathrm{MCHC}$ are negatively related to leukocyte and ANC. Notably, the native relationships were strong between $\mathrm{AEC}$ and $\mathrm{ANC}$, and ALC and ANC.

\section{Kinetics of hematologic responses to disease activity}

To monitor the kinetics of hematologic responses and disease regression, we look into three individual patients who had blood samples of more than five time points during the course available for this analysis (patients 1,2, and 3). Patient 1 was classified into a moderate disease with 2 into a severe disease and 3 into a critically ill disease.

Patient 1 was an 81-year-old male who had a fever, chest pain, and cough on February 6. A chest CT scan on February 14 revealed ground-glass lesions in the right lower lung. Positive SARS-CoV-2 was tested by RT-PCR assay of a throat swab specimen on February 17 . Laboratory tests indicated lymphocytopenia $\left(0.83 \times 10^{9} / \mathrm{L}\right)$, eosinopenia $\left(0 \times 10^{9} /\right.$ $\mathrm{L})$, and monocytosis $\left(0.66 \times 10^{9} / \mathrm{L}\right)$ with increased CRP (Fig.
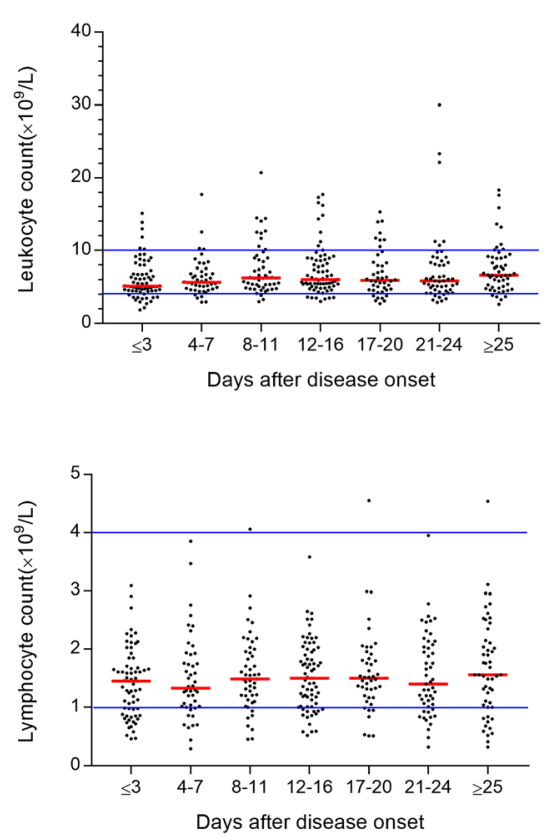
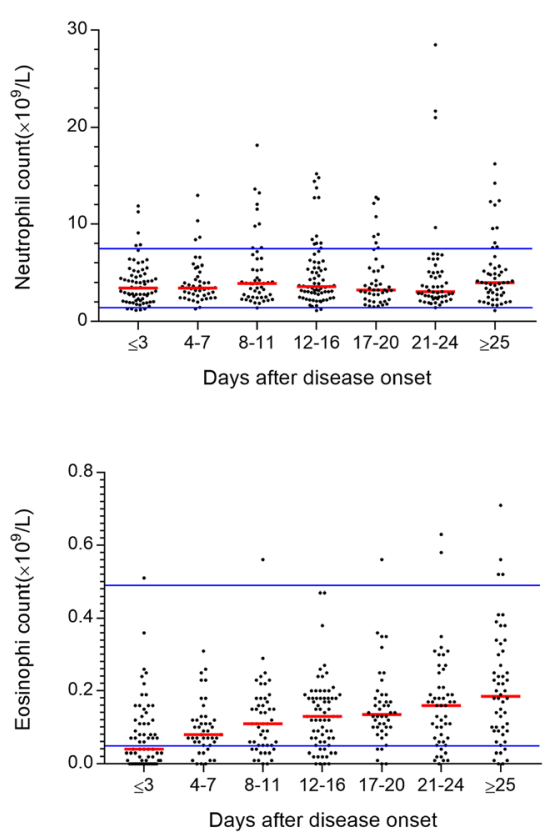
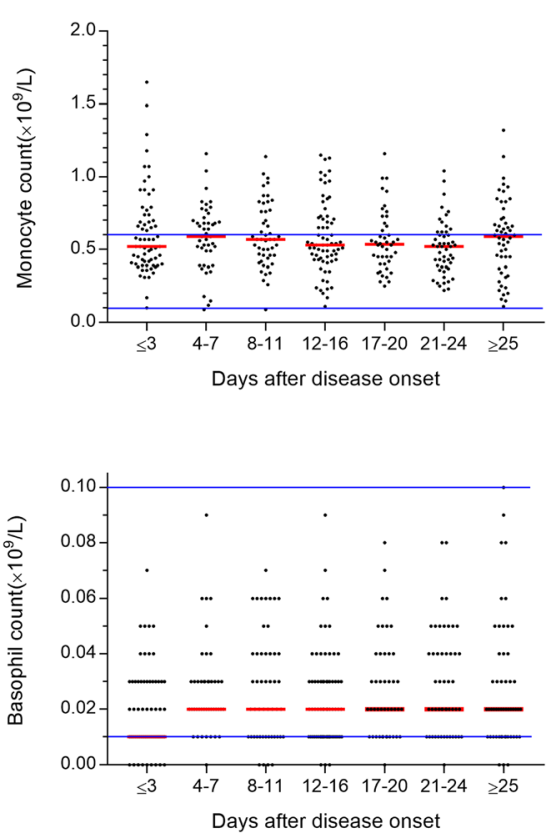

Fig. 1 Absolute counts of leukocyte, neutrophil, monocyte, lymphocyte, eosinophil, and basophil during COVID-19. Median values are represented. The solid lines in blue show the upper and the lower normal limits of each parameter 

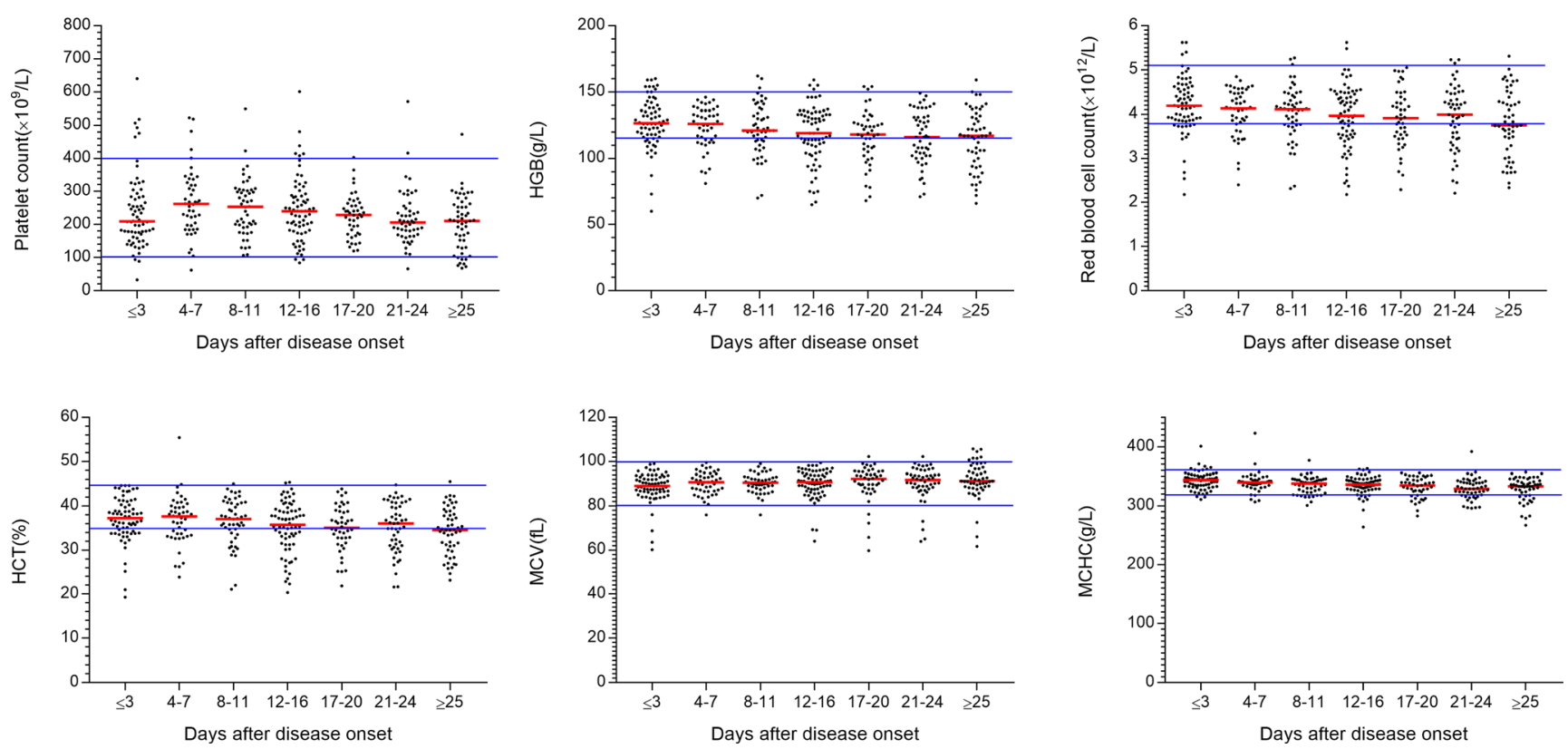

Fig. 2 Levels of platelet, hemoglobin (HGB), red blood cell (RBC), hematocrit $(\mathrm{HCT})$, mean corpuscular volume (MCV), and mean cell hemoglobin concentration (MCHC) during COVID-19. Median values

are represented. The solid lines in blue show the upper and the lower normal limits of each parameter

4a-1). His symptoms and CT findings significantly improved after treated with Arbidol, Ribavirin, Moxifloxacin, Lianhua Qingwen capsules, and Thymosin and supportive care (Fig. $4 \mathrm{a}-2)$. The patient was discharged with lymphocytes at $1.56 \times$ $10^{9} / \mathrm{L}$ on March 12 after repeated negative RT-PCR detections.

Patient 2 was a 72-year-old woman who had a fever and dizziness. A chest CT scan revealed bilateral scattered patchy lesions. Positive novel coronavirus nucleic acid by RT-PCR and positive IgG antibodies against SARS-CoV-2 supported the diagnosis of the virus infection. Two days after admission, she complained of dyspnea with an oxygen saturation of $92 \%$ while breathing ambient air. Laboratory tests showed leukocytosis $\left(17.73 \times 10^{9} / \mathrm{L}\right)$, neutrophilia $\left(12.98 \times 10^{9} / \mathrm{L}\right)$, monocytosis $\left(1.16 \times 10^{9} / \mathrm{L}\right)$, and eosinopenia $\left(0.01 \times 10^{9} / \mathrm{L}\right)$ but the normal concentration of CRP, PCT, and IL-6 (Fig. 4b1). She was treated with Arbidol, Moxifloxacin, methylprednisolone for 5 days, oxygen supply, and supportive care.
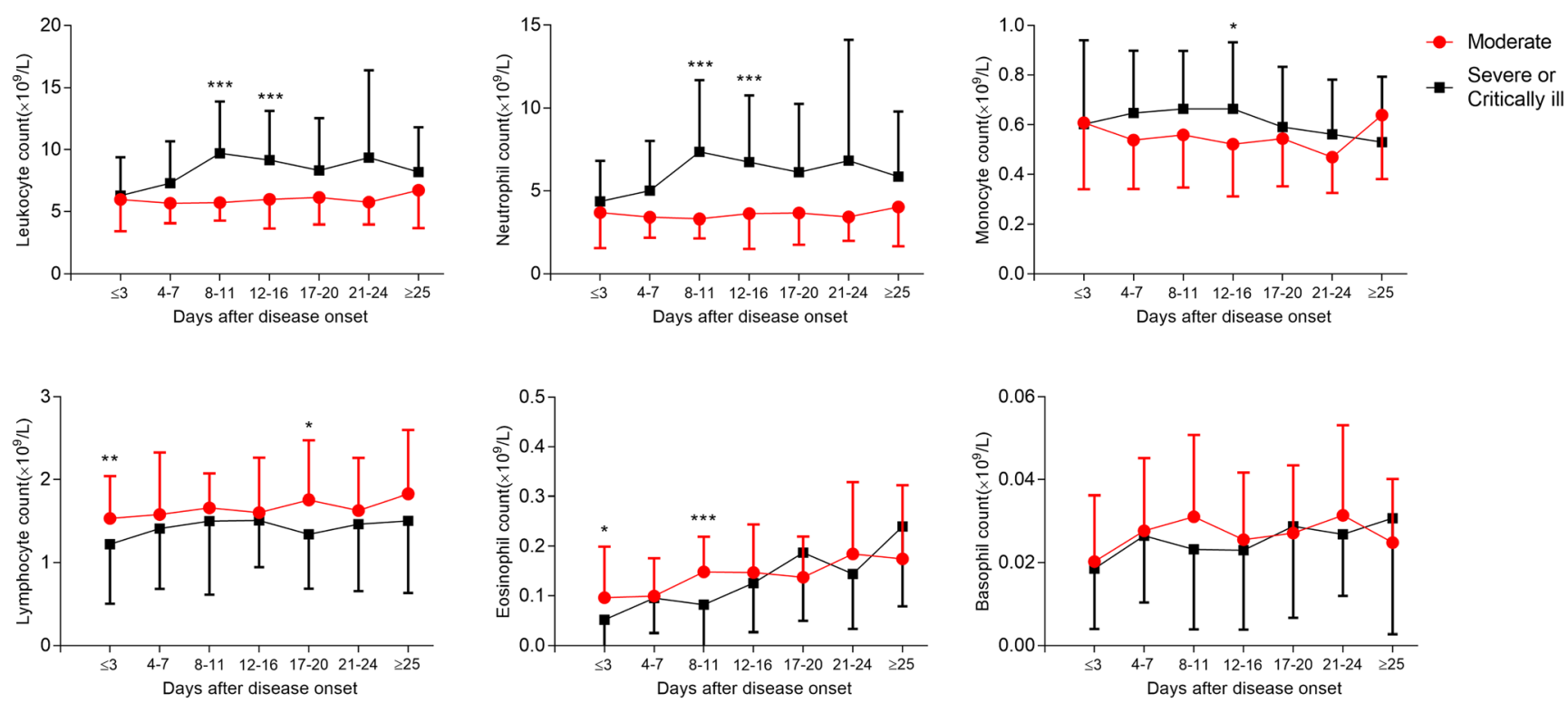

Fig. 3 Analyses of the difference between the classification of COVID-19 (moderate vs. severe or critically ill) in hematologic changes (A, B). Mean and SD are represented. $* P<0.05, * * P<0.01, * * * P<0.001$ 

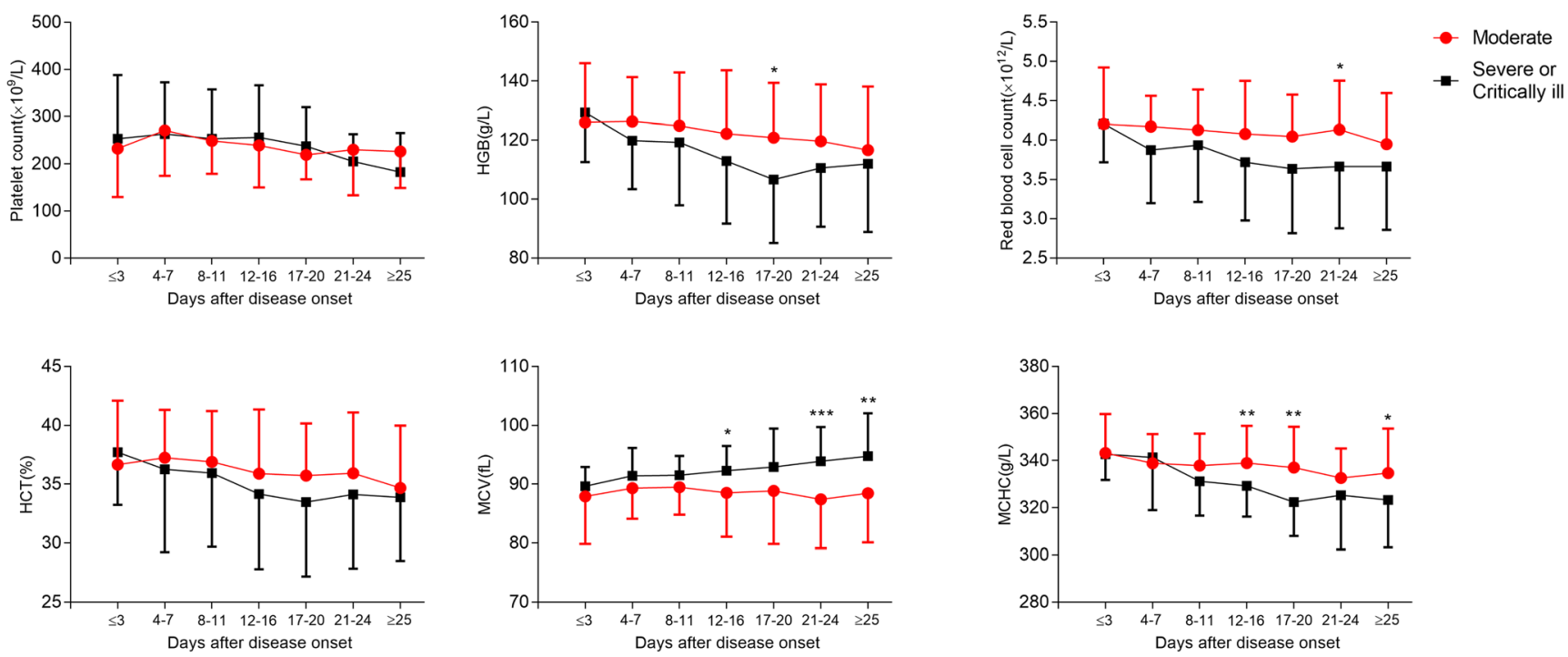

Fig. 3 continued.

Hydroxychloroquine replaced Arbidol since February 25. A chest CT scan on March 12 indicated a significant reduction of lesions (Fig. 4b-2), and the oxygen saturation remained above $95 \%$ in ambient air. She was discharged on March 15 with normal blood cell counts after two consecutive negative RTPCR tests.

Patient 3 was a 57-year-old male who had a fever and chest tightness on February 4. Chest CT revealed bilateral scattered patchy opacities. Although RT-PCR for SARS-CoV-2 was negative for four times, positive $\operatorname{IgM}$ and positive $\operatorname{IgG}$ antibodies against this virus on March 13 confirmed the diagnosis of COVID-19. The CBC was within normal ranges, except for lymphocytopenia $\left(0.44 \times 10^{9} / \mathrm{L}\right)$ and an increased CRP concentration (84.3 $\mathrm{mg} / \mathrm{L})$ on admission (Fig. 4c-1). Oral Arbidol and Lianhua Qingwen capsules were administered, together with oxygen for delivery by nasal cannula $(3-5 \mathrm{~L} / \mathrm{min})$. The patient complained of cough, expectoration, and shortness of breath since February 20. The second chest CT scan showed diffuse groundglass opacities with scattered consolidation (Fig. 4c-2). Ribavirin, short-term methylprednisolone, and intravenous immunoglobulin therapy were initiated. Oxygen saturation remained at $95 \%$ with oxygen for delivery by nasal cannula $(8 \mathrm{~L} / \mathrm{min})$. Significant abnormalities in the $\mathrm{CBC}$ were found on February 28, including leukocytosis $\left(10.04 \times 10^{9} / \mathrm{L}\right)$, neutrophilia $\left(7.96 \times 10^{9} / \mathrm{L}\right)$, monocytosis $\left(0.71 \times 10^{9} / \mathrm{L}\right)$, and eosinopenia $(0.04 \times$ $\left.10^{9} / \mathrm{L}\right)$. Lymphocyte count dropped sharply from 1.21 $\times 10^{9} / \mathrm{L}$ on February 28 to $0.51 \times 10^{9} / \mathrm{L}$ on March 3 . In addition, levels of CRP $(67.5 \mathrm{mg} / \mathrm{L})$ and IL-6 (76.6 $\mathrm{pg} / \mathrm{mL}$ ) concentration increased significantly. On February 30 , the patient developed respiratory failure and was subjected to high-flow nasal cannula and then non-invasive mechanical ventilation. Fortunately, his symptoms were relieved after tocilizumab therapy to target cytokine storm. He successfully detached from non-invasive mechanical ventilation and received oxygen by nasal cannula ( $5 \mathrm{~L} / \mathrm{min}$ ) on March 13 . Serial $\mathrm{CBC}$ analysis and CRP concentration returned to normal. Interestingly, the concentration of IL-6 peaked (928.8 pg/mL) on March 4 and then decreased slowly to $81.42 \mathrm{pg} / \mathrm{mL}$ on March 16. He was transferred to another hospital for further rehabilitation therapy on March 17.

\section{Discussion}

COVID-19 presents as a newly recognized pneumonia that has brought about a global pandemic and drastically impacts the world. Although respiratory symptoms dominated the clinical manifestations of COVID-19, abnormal hematologic profiles were frequently observed. Eosinopenia (37.80\%), monocytosis $(51.97 \%)$, lymphocytopenia (25.20\%), and anemia $(51.97 \%)$ were the most common hematologic findings in our cohort of 127 patients with COVID-19.

The levels of changes in leukocytes, neutrophils, lymphocytes, monocytes, eosinophils, basophils, platelets, $\mathrm{HGB}, \mathrm{MCV}$, and $\mathrm{MCHC}$ are overall associated with lung involvement, oxygen demand, and disease activity. Nonetheless, delta of AEC (end hospitalizationbaseline) and delta of $\mathrm{ABC}$ (Max-Min) may be used as an indicator for delayed recovery of COVID-19 patients in multivariate analysis. Continuously increasing eosinophils in the late phase of COVID-19 kept pace 
Table 3 Multiple linear regression analysis for duration of hospital stays in patients with COVID-19

\begin{tabular}{|c|c|c|c|c|}
\hline \multirow[t]{3}{*}{ Variables } & \multicolumn{4}{|l|}{ Duration of hospital stay } \\
\hline & \multicolumn{2}{|l|}{ Univariate } & \multicolumn{2}{|l|}{ Multivariate } \\
\hline & Coefficients $(95 \% \mathrm{CI})$ & $P$ value & Coefficients $(95 \% \mathrm{CI})$ & $P$ value \\
\hline $\operatorname{Sex}(\mathrm{M} / \mathrm{F})$ & $0.87(-1.26$ to 3.01$)$ & 0.42 & & \\
\hline Age & $0.05(-0.03$ to 0.14$)$ & 0.20 & & \\
\hline Comorbidities (yes/no) & $2.52(0.40$ to 4.64$)$ & 0.02 & $2.267(0.311$ to 4.223$)$ & 0.024 \\
\hline Onset of symptom to hospital admission (days) & $-0.11(-0.24$ to 0.02$)$ & 0.10 & & \\
\hline Lung region distribution $(\mathrm{CT}$, bilateral/unilateral) & $0.47(-4.56$ to 5.50$)$ & 0.85 & & \\
\hline Degree of lung involvement $(\mathrm{CT},<25 \% / 25-50 \% />50 \%)$ & $1.40(-0.19$ to 3.00$)$ & 0.08 & & \\
\hline Transverse distribution (CT, peripheral/diffuse) & $0.88(-1.27$ to 3.02$)$ & 0.42 & & \\
\hline Oxygen supply & $1.82(0.43$ to 3.22$)$ & 0.01 & & \\
\hline Leukocyte count at admission $\left(\times 10^{9} / \mathrm{L}\right)$ & $0.03(-0.39$ to 0.46$)$ & 0.87 & & \\
\hline Delta leukocyte count $\left(\times 10^{9} / \mathrm{L}\right) !$ & $0.60(0.07$ to 1.13$)$ & 0.03 & & \\
\hline Delta leukocyte count $\left(\times 10^{9} / \mathrm{L}\right) ! !$ & $0.43(0.12$ to 0.73$)$ & 0.01 & & \\
\hline ANC at admission $\left(\times 10^{9} / \mathrm{L}\right)$ & $0.19(-0.33$ to 0.71$)$ & 0.47 & & \\
\hline Delta ANC $\left(\times 10^{9} / \mathrm{L}\right) !$ & $0.58(-0.001$ to 1.163$)$ & 0.05 & & \\
\hline Delta ANC $\left(\times 10^{9} / \mathrm{L}\right) ! !$ & 0.41 (0.09 to 0.73$)$ & 0.01 & & \\
\hline ALC at presentation $\left(\times 10^{9} / \mathrm{L}\right)$ & $-1.05(-2.74$ to 0.64$)$ & 0.22 & & \\
\hline Delta ALC $\left(\times 10^{9} / \mathrm{L}\right)$ ! & $3.66(1.10$ to 6.21$)$ & 0.005 & & \\
\hline Delta ALC $\left(\times 10^{9} / \mathrm{L}\right) ! !$ & $3.49(1.17$ to 5.81$)$ & 0.003 & & \\
\hline AMC at presentation $\left(\times 10^{9} / \mathrm{L}\right)$ & $1.22(-2.88$ to 5.32$)$ & 0.56 & & \\
\hline Delta AMC $\left(\times 10^{9} / \mathrm{L}\right) !$ & $8.49(1.77$ to 15.20$)$ & 0.014 & & \\
\hline Delta AMC $\left(\times 10^{9} / \mathrm{L}\right) ! !$ & $8.60(4.01$ to 13.19$)$ & $<0.001$ & & \\
\hline $\mathrm{AEC}$ at presentation $\left(\times 10^{9} / \mathrm{L}\right)$ & $-13.45(-25.78$ to -1.13$)$ & 0.03 & & \\
\hline Delta $\operatorname{AEC}\left(\times 10^{9} / \mathrm{L}\right) !$ & 14.27 (4.91 to 23.64$)$ & 0.003 & $10.32(1.03$ to 19.60$)$ & 0.030 \\
\hline Delta AEC $\left(\times 10^{9} / \mathrm{L}\right) ! !$ & 12.27 (4.00 to 20.53$)$ & 0.004 & & \\
\hline $\mathrm{ABC}$ at presentation $\left(\times 10^{9} / \mathrm{L}\right)$ & $3.31(-55.19$ to 61.81$)$ & 0.91 & & \\
\hline Delta $\mathrm{ABC}\left(\times 10^{9} / \mathrm{L}\right) !$ & 71.35 (10.27 to 132.43$)$ & 0.02 & & \\
\hline Delta $\mathrm{ABC}\left(\times 10^{9} / \mathrm{L}\right) ! !$ & $120.21(57.74$ to 182.68$)$ & $<0.001$ & $71.43(8.55$ to 134.31$)$ & 0.026 \\
\hline Platelet count at presentation $\left(\times 10^{9} / \mathrm{L}\right)$ & $-0.0005(-0.01$ to 0.010$)$ & 0.92 & & \\
\hline Delta PLT $\left(\times 10^{9} / \mathrm{L}\right) !$ & $0.020(0.003$ to 0.036$)$ & 0.019 & & \\
\hline Delta PLT $\left(\times 10^{9} / \mathrm{L}\right) ! !$ & $0.027(0.012$ to 0.041$)$ & 0.001 & & \\
\hline HGB at presentation $(\mathrm{g} / \mathrm{L})$ & $-0.008(-0.067$ to 0.051$)$ & 0.79 & & \\
\hline Delta HGB $(g / L) !$ & $0.130(0.024$ to 0.236$)$ & 0.016 & & \\
\hline Delta HGB (g/L)!! & $0.144(0.049$ to 0.238$)$ & 0.003 & & \\
\hline $\mathrm{MCV}$ at presentation (fL) & $-0.10(-0.26$ to 0.06$)$ & 0.23 & & \\
\hline Delta MCV (fL)! & $0.438(-0.048$ to 0.924$)$ & 0.077 & & \\
\hline Delta MCV (fL)!! & $0.501(0.093$ to 0.909$)$ & 0.016 & & \\
\hline $\mathrm{MCHC}$ at presentation $(\mathrm{g} / \mathrm{L})$ & $0.02(-0.05$ to 0.08$)$ & 0.55 & & \\
\hline Delta MCHC (g/L)! & $0.056(-0.019$ to 0.132$)$ & 0.144 & & \\
\hline Delta MCHC (g/L)!! & $0.077(0.011$ to 0.143$)$ & 0.023 & & \\
\hline
\end{tabular}

$M$, male; $F$, female; $A N C$, absolute neutrophil count; $A L C$, absolute lymphocyte count; $A M C$, absolute monocyte count; $A E C$, absolute eosinophil count; $A B C$, absolute basophil count; PLT, platelet; $H G B$, hemoglobin; $M C V$, mean corpuscular volume; $M C H C$, mean cell hemoglobin concentration. Delta $!=$ end hospitalization - baseline; Delta $! !=$ Max - Min

with radiographic and virology improvements in these recovered patients. Importantly, eosinophils of moderate patients restored earlier than those of severe or more patients, suggesting that dynamical eosinophils may be the clue of COVID-19 recovery. Eosinophils were formerly believed to defend against helminths and are 


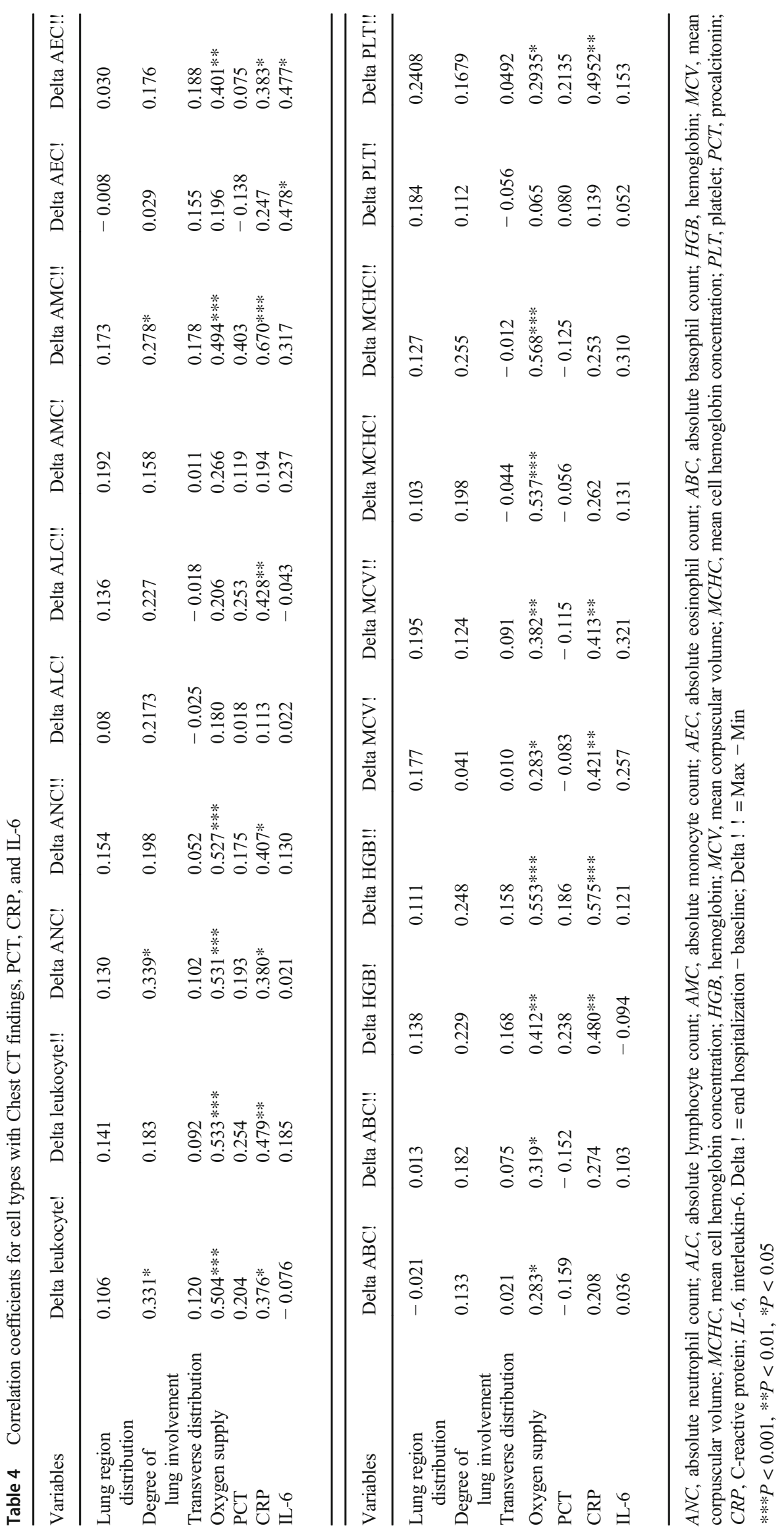




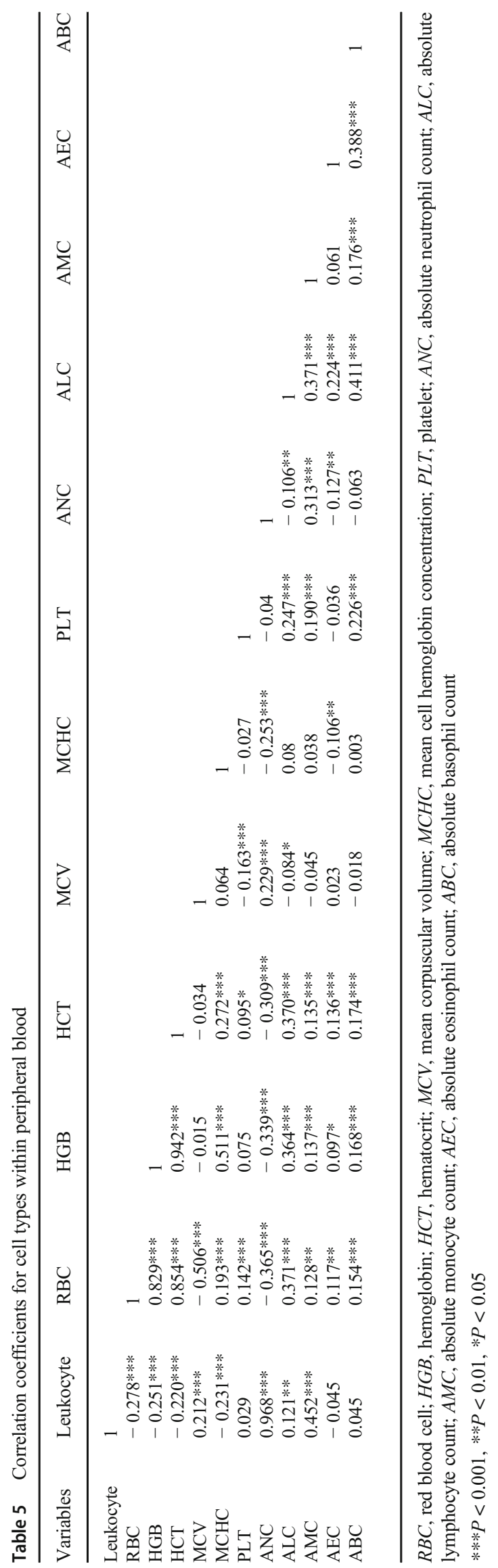

increasingly understood to play an essential role in virus infections, including respiratory syncytial virus, influenza viruses, and even HIV infection [12-15]. Moreover, EDN produced by eosinophils is a ribonuclease with significant antiviral activity [16]. It was reported that the number of eosinophils in peripheral blood is decreasing rapidly and persistently in acute infection or inflammation $[17,18]$, and eosinopenia actually appeared in the majority of COVID-19 patients [6, 19, 20].

Severe COVID-19 cases were reported to have lower percentages of monocytes compared to non-severe cases $[6,19]$, but we found that more than half of our recovered patients had monocytes higher than $0.6 \times 10^{9} / \mathrm{L}$. Excessive non-effective host immune responses partially by inflammatory monocytes may associate with severe lung pathology in COVID-19 patients [19], which accounts for IL-6 blockade therapy [21]. Most COVID-19 patients also had marked lymphocytopenia, and nonsurvivors developed more severe lymphocytopenia over time $[5,6,22]$. Lymphocytopenia seems to be associated with disease activity and mortality, particularly among the elderly [20]. However, lymphocytopenia is less frequent in the present study compared to those deceased patients or patients in intensive care unit [5, 10, 23].

Progressive anemia with elevating MCV and decreasing MCHC took place in our cohort. Peak MCV and nadir $\mathrm{MCHC}$ are independent predictors of disease deterioration in this recovered population. Hypoplastic bone marrow induced by COVID-19 and side effects by Ribavirin or chloroquine treatment may cause anemia [24]. Iron deficiency or vitamin $B_{12}$ and folate deficiency resulting from poor appetite and anxieties of those patients with COVID-19 could be another important reason, although evidence is lack in this critical condition. Hematologic findings could not result from glucocorticoid exposure as nearly all patients had not received steroids at admission, but the activation of the hypothalamic-pituitary-adrenal axis in critically ill disease cannot be ruled out. In the case of COVID-19, this virus may directly damage the hematopoietic and immune system, as hypoplastic bone marrow and decreased numbers of lymphocyte, cell degeneration, and necrosis in the spleen were found pathologically in three cases [24].

This study has several limitations. First, only four critically ill patients are enrolled. However, these patients recovered, and we have described 1 of them in detail. The cohort in the present study unfolds the realworld situation where most COVID-19 patients, including moderate, severe, or critically ill patients, in hospitals finally recovered. Second, some specific detections 


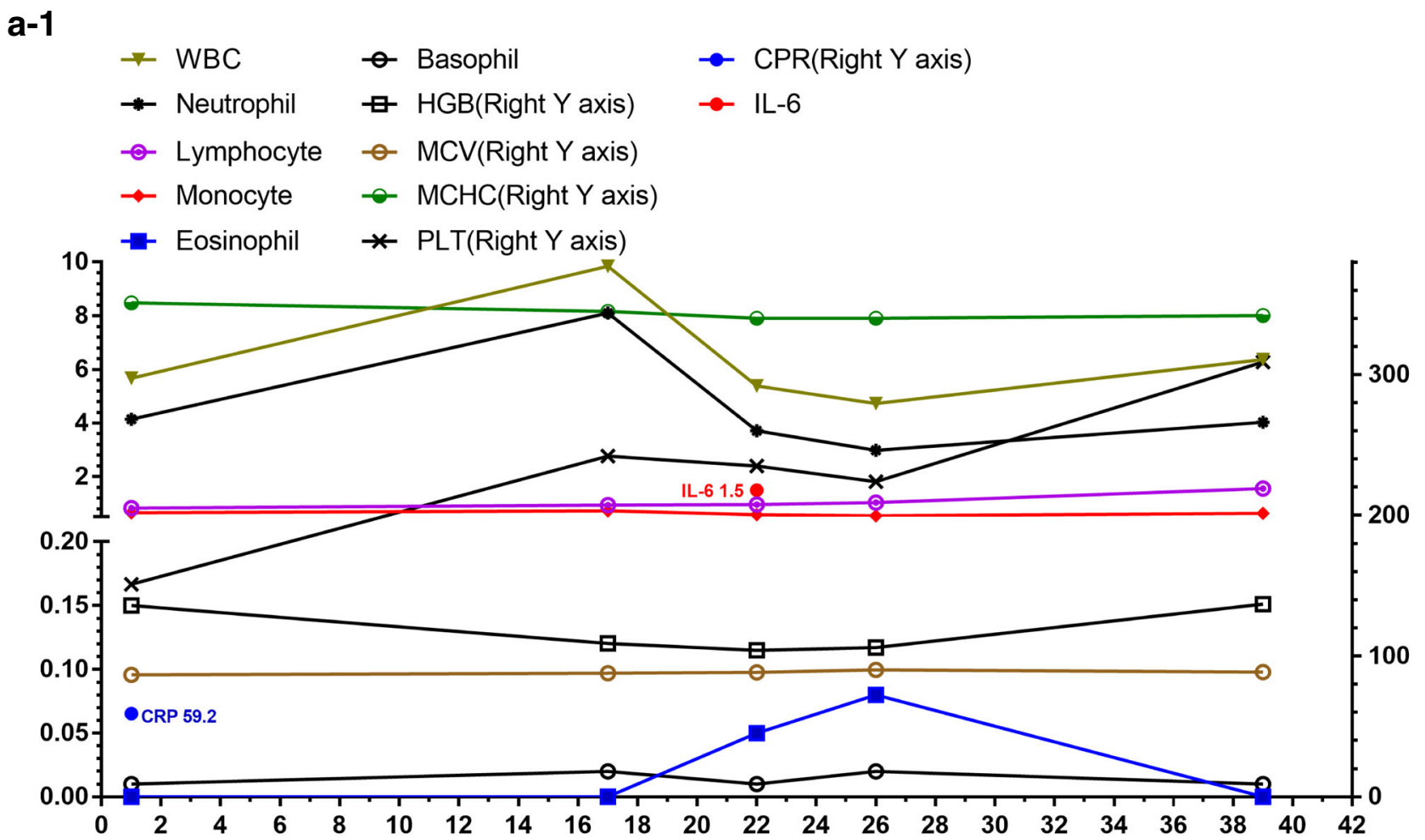

a-2

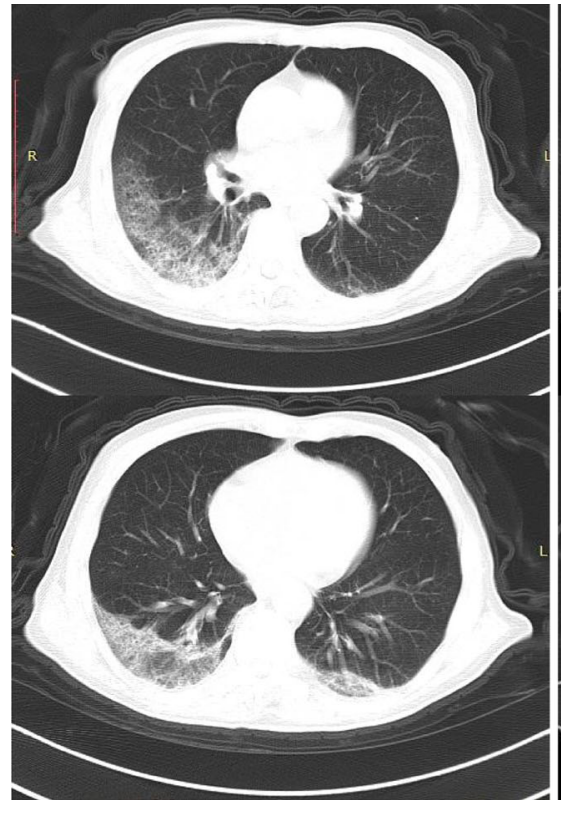

Feb 14

(d1)

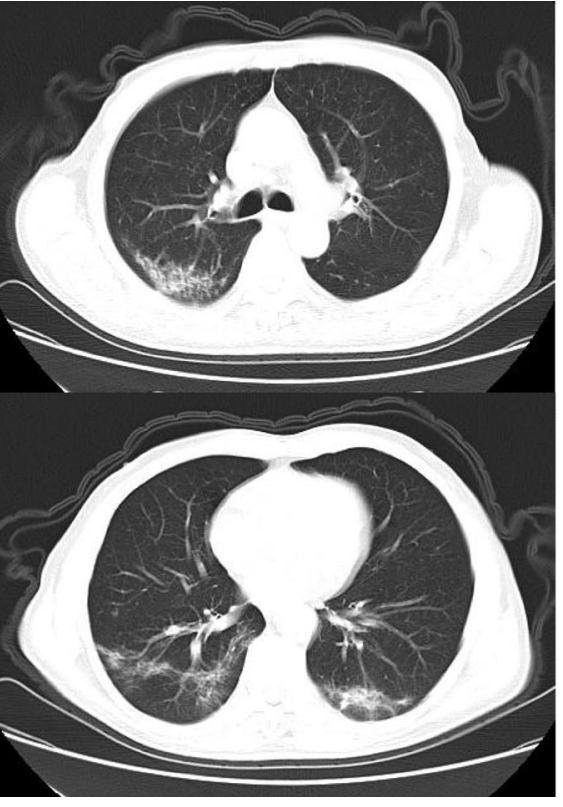

Feb 28

(d15)

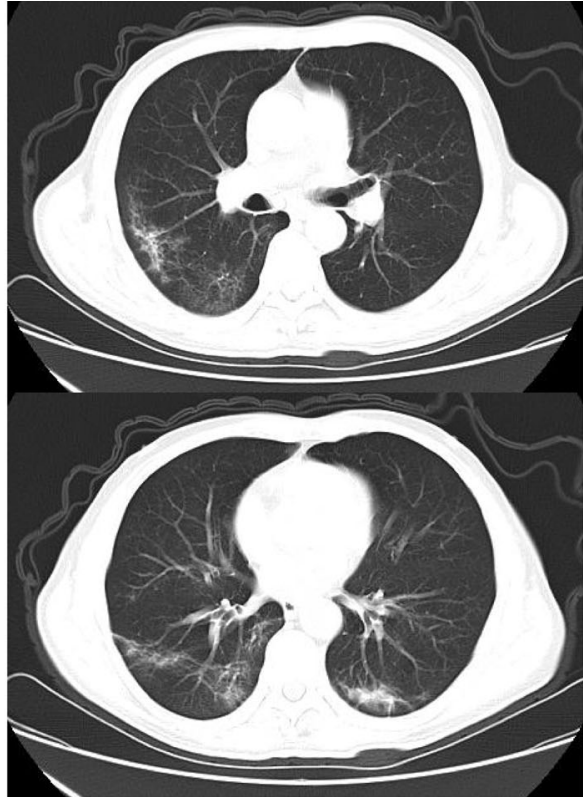

March 6

(d22)

Fig. 4 Individual plots of subsets and profiles of peripheral blood cells against the day of disease in 3 patients (a-1 c-1). Serial chest CT images of 3 patients during hospital stay (a-2 c-2)

about these patients were missing, such as bone marrow smear, the level of iron, vitamin $\mathrm{B}_{12}$, or folate, reticulocyte count, and Coomb's test. Nonetheless, the data on $\mathrm{CBC}$, serum biochemistry, supportive care, and the duration of hospital stay is admittedly supportive. Third, this is a retrospective study. A small number of patients 


\section{b-1}

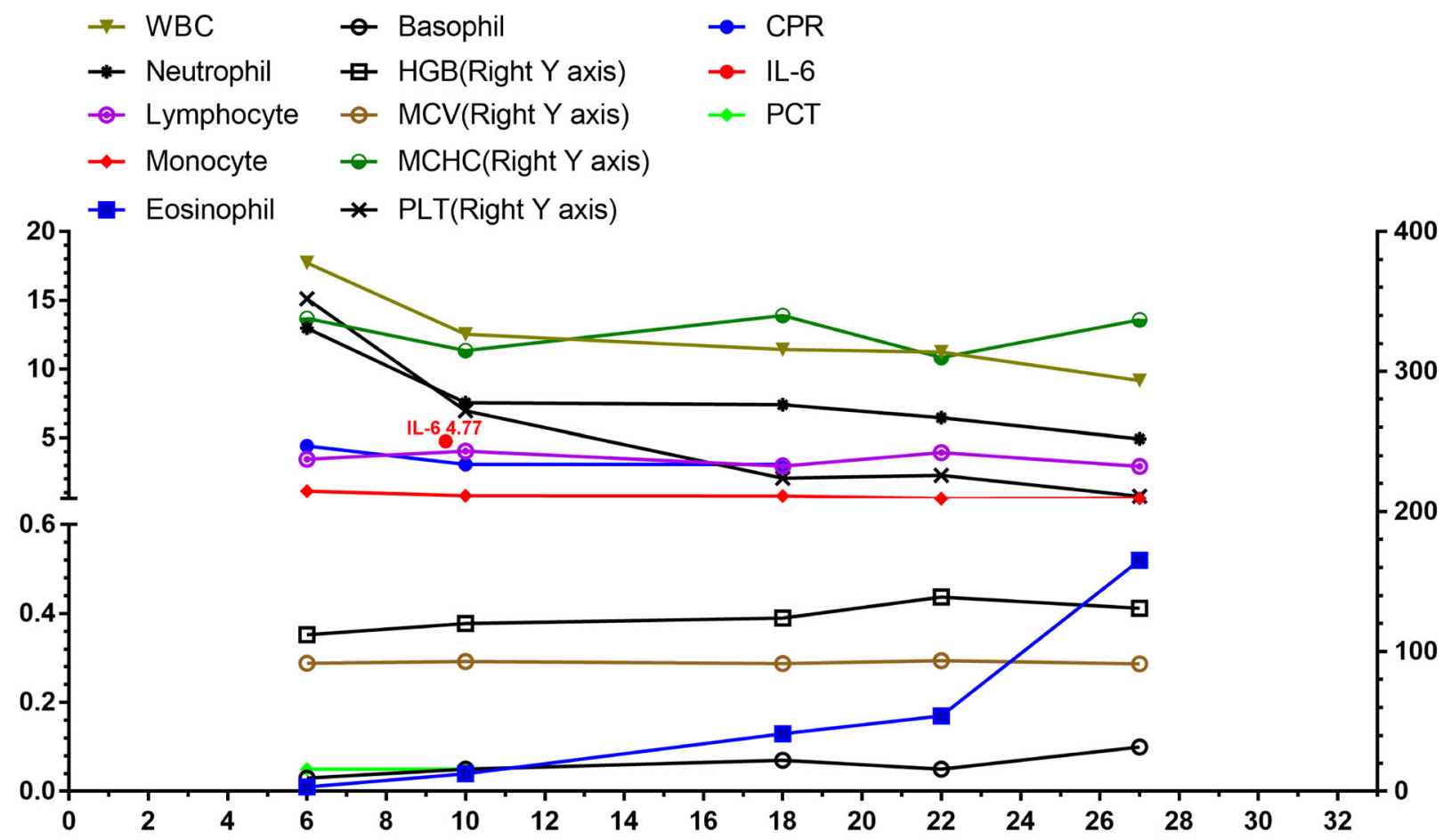

\section{b-2}

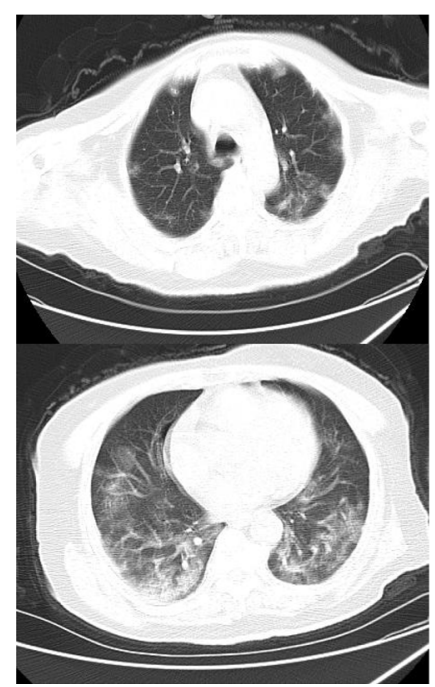

Feb 16

(d2)

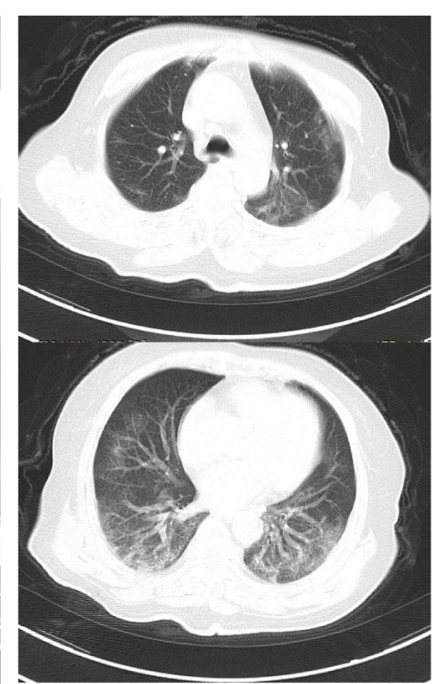

Feb 23

(d9)

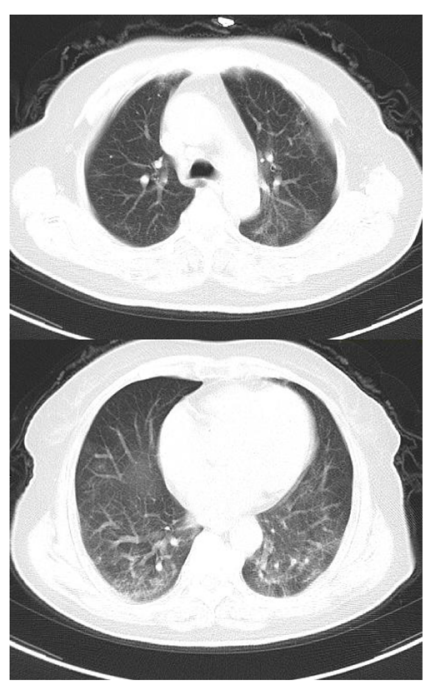

March 2

(d17)

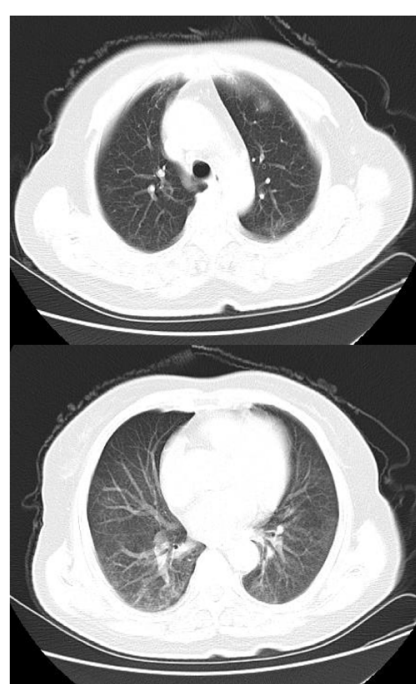

March 12

(d27)

Fig. 4 continued.

had laboratory tests only on admission without dynamic changes. The time of sampling of our patients was variable, but we pooled the data at a certain period, for example, 3-4 days in the analysis.
In conclusion, eosinopenia, monocytosis, lymphocytopenia, and anemia were common among recovered cases with COVID-19 in our study, but dynamics of eosinophils and basophils may be used as an indicator for delayed recovery. 


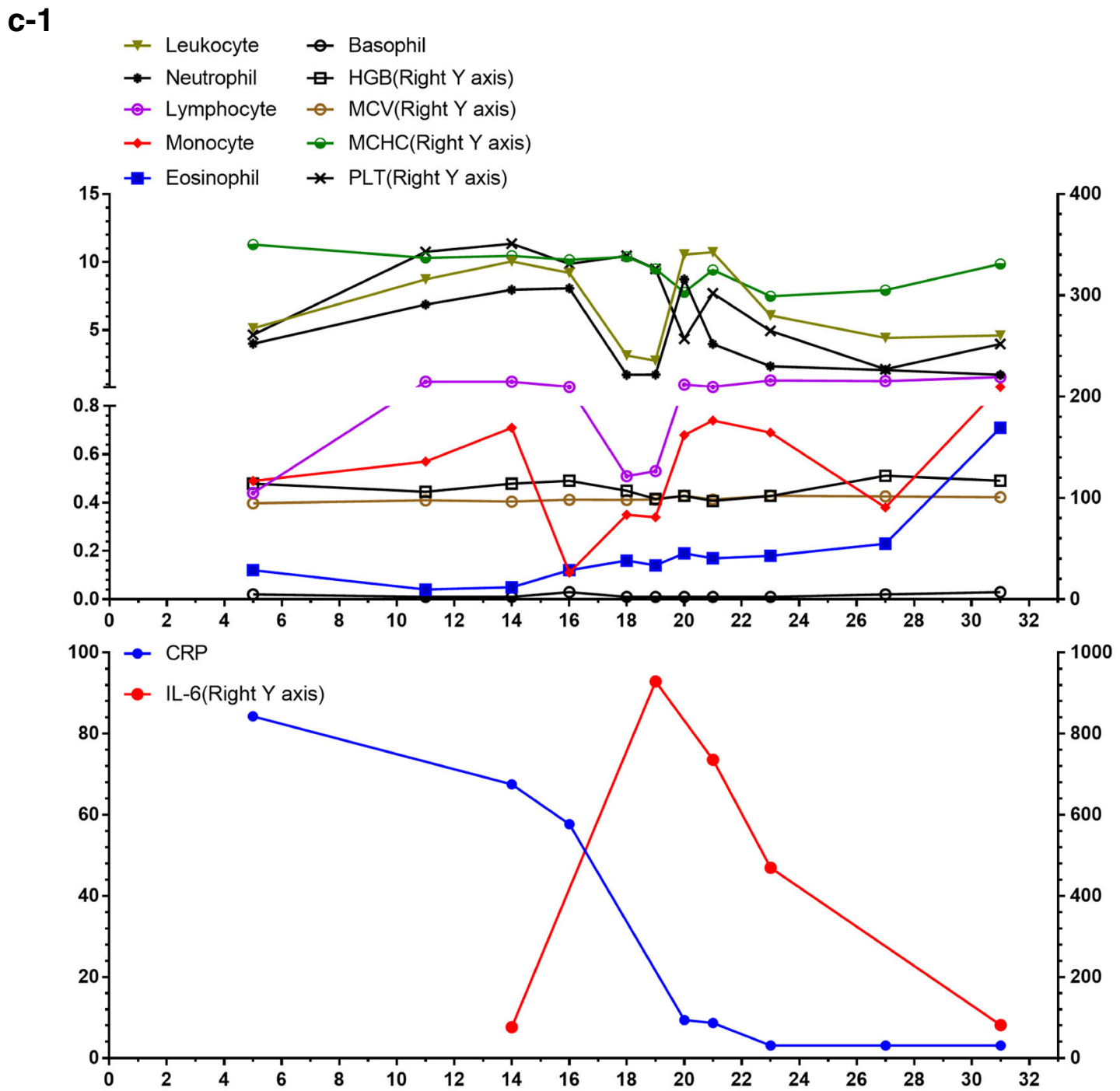

\section{c-2}

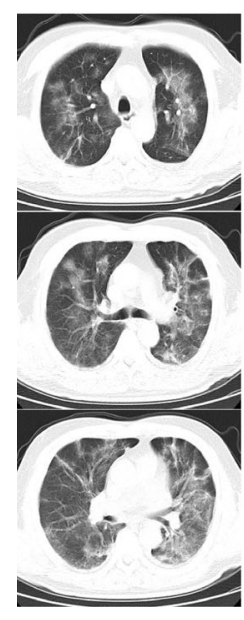

Feb 19

(d5)
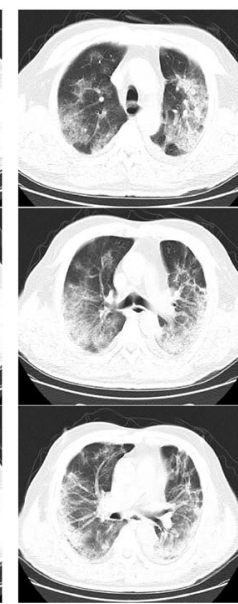

(d12)

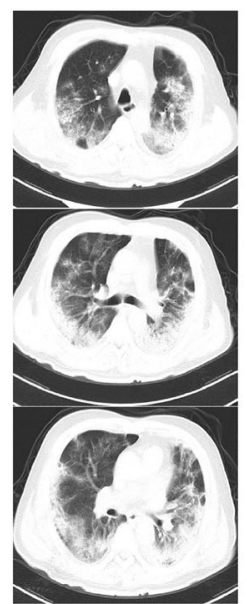

March 2

(d17)

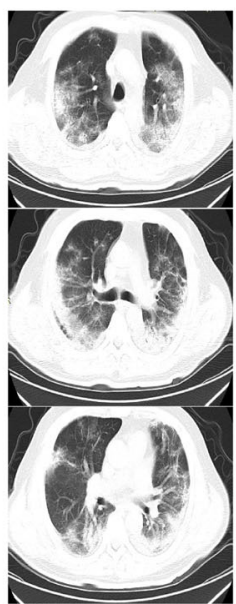

March 5

(d20)

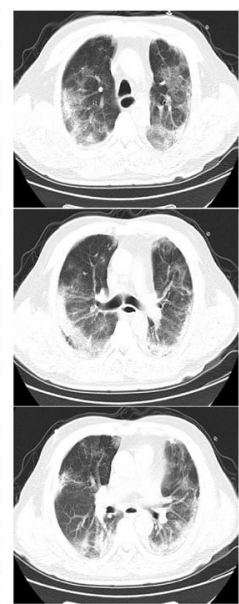

March 11

(d26)

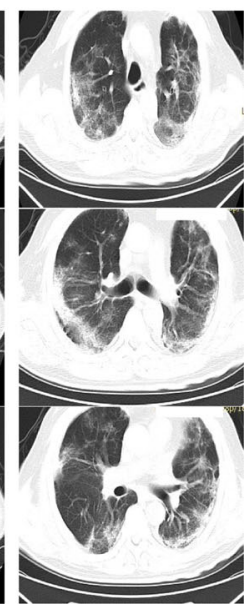

March 17

(d32)

Fig. 4 continued. 
Further studies are needed to investigate their underlying mechanisms in COVID-19 patients.

Supplementary Information The online version contains supplementary material available at https://doi.org/10.1007/s00277-021-04426-x.

Acknowledgments We thank all the patients, their families, and healthcare workers involved in this study.

Contributors Xiao-Hua Luo conceptualized the study, had full access to all data in this study, and is responsible for the integrity and accuracy of the data analysis. Jian Mao and Rong Dai contributed equally to this work and share the first authorship. Jian Mao, Rong Dai, Rui-Chan Du, and LiPing Shui contributed to data collection, data analysis, data interpretation, and literature search. Rong Dai and Yan Zhu contributed to the critical revision of this report. All authors approved the final draft of the manuscript.

\section{Compliance with ethical standards}

Conflict of interest The authors declare that they have no conflict of interest.

\section{References}

1. Zhu N, Zhang D, Wang W, Li X, Yang B, Song J et al (2020) A novel coronavirus from patients with pneumonia in China, 2019. N Engl J Med

2. Holshue ML, DeBolt C, Lindquist S, Lofy KH, Wiesman J, Bruce $\mathrm{H}$ et al (2020) First case of 2019 novel coronavirus in the United States. N Engl J Med

3. WHO. Novel coronavirus (2019-nCoV) situation report - July 15, 2020. https://www.who.int/docs/default-source/coronaviruse/ situation-reports/20200715-covid-19-sitrep-177.pdf?sfvrsn= b1a193f3 2 (accessed July 16, 2020).

4. Lam TT-Ȳ, Shum MH-H, Zhu H-C, Tong Y-G, Ni X-B, Liao Y-S, et al. (2020) Identifying SARS-CoV-2 related coronaviruses in Malayan pangolins. Nature 2020/03/26

5. Wang D, Hu B, Hu C, Zhu F, Liu X, Zhang J et al (2020) Clinical characteristics of 138 hospitalized patients with 2019 novel coronavirus-infected pneumonia in Wuhan, China. Jama.

6. Qin C, Zhou L, Hu Z, Zhang S, Yang S, Tao Y et al (2020) Dysregulation of immune response in patients with COVID-19 in Wuhan, China. Clin Infect Dis

7. Chen R, Sang L, Jiang M, Yang Z, Jia N, Fu W et al (2020) Longitudinal hematologic and immunologic variations associated with the progression of COVID-19 patients in China. J Allergy Clin Immunol

8. Li Q, Cao Y, Chen L, Wu D, Yu J, Wang H et al (2020) Hematological features of persons with COVID-19. Leukemia.:110

9. National Health Commission of the People's Republic of China (2020) The 5th trial version of Diagnosis and Treatment Scheme for Pneumonitis with 2019-nCoV Infection (In Chinese). http:// w w w. n h c.gov.c n/yzy g j/s 7653 p/ $202003 /$ 46c9294a7dfe4cef80dc7f5912eb1989shtml

10. Chen T, Wu D, Chen H, Yan W, Yang D, Chen G et al (2020) Clinical characteristics of 113 deceased patients with coronavirus disease 2019: retrospective study. bmj. 368

11. National Health Commission of the People's Republic of China (2020) The 6th trial version of Diagnosis and Treatment Scheme for Pneumonitis with 2019-nCoV Infection (In Chinese). http:// w w w.n h c.gov.cn/y z y g j/s 7653 p/202002/ 8334a8326dd94d329df351d7da8aefc2.shtml

12. Harrison AM, Bonville CA, Rosenberg HF, Domachowske JB (1999) Respiratory syncytical virus-induced chemokine expression in the lower airways: eosinophil recruitment and degranulation. Am J Respir Crit Care Med 159(6):1918-1924

13. Samarasinghe AE, Melo RC, Duan S, LeMessurier KS, Liedmann S, Surman SL et al (2017) Eosinophils promote antiviral immunity in mice infected with influenza A virus. J Immunol 198(8):3214 3226

14. Cohen AJ, Steigbigel RT (1996) Eosinophilia in patients infected with human immunodeficiency virus. J Infect Dis 174(3):615-618

15. Phipps S, Lam CE, Mahalingam S, Newhouse M, Ramirez R, Rosenberg HF et al (2007) Eosinophils contribute to innate antiviral immunity and promote clearance of respiratory syncytial virus. Blood J Am Soc Hematol 110(5):1578-1586

16. Gleich GJ, Loegering DA (1984) Immunobiology of eosinophils. Annu Rev Immunol 2(1):429-459

17. Gleich GJ (2000) Mechanisms of eosinophil-associated inflammation. J Allergy Clin Immunol 105(4):651-663

18. Abidi K, Belayachi J, Derras Y, El Khayari M, Dendane T, Madani $\mathrm{N}$ et al (2011) Eosinopenia, an early marker of increased mortality in critically ill medical patients. Intensive Care Med 37(7):11361142

19. Zhou Y, Fu B, Zheng X, Wang D, Zhao C, Sun R et al (2020) Pathogenic $T$ cells and inflammatory monocytes incite inflammatory storm in severe COVID-19 patients. Natl Sci Rev

20. Zhang J, Dong X, Cao YY, Yuan Y, Yang Y, Yan Y et al (2020) Clinical characteristics of 140 patients infected by SARS-CoV-2 in Wuhan, China. Allergy.

21. Norelli M, Camisa B, Barbiera G, Falcone L, Purevdorj A, Genua $M$ et al (2018) Monocyte-derived IL-1 and IL-6 are differentially required for cytokine-release syndrome and neurotoxicity due to CAR T cells. Nat Med 24(6):739-748

22. Liu J, Li S, Liu J, Liang B, Wang X, Wang H et al (2020) Longitudinal characteristics of lymphocyte responses and cytokine profiles in the peripheral blood of SARS-CoV-2 infected patients. EBioMedicine.: 102763

23. Huang C, Wang Y, Li X, Ren L, Zhao J, Hu Y et al (2020) Clinical features of patients infected with 2019 novel coronavirus in Wuhan, China. Lancet

24. Yao X, Li T, He Z, Ping Y, Liu H, Yu S et al (2020) A pathological report of three COVID-19 cases by minimally invasive autopsies. Zhonghua bing li xue za zhi= Chin J Pathol 49:E009

Publisher's note Springer Nature remains neutral with regard to jurisdictional claims in published maps and institutional affiliations. 